\title{
corpespondence
}

\section{NOAA-5 Views Dust Storm}

Charles H. Vermillion, Earth Observation Systems Division, Applications Directorate, NASA, Goddard Space Flight Center, Greenbelt, Md. 20771

A dust storm, reminiscent of the 1930s, is imaged in two successive passes of the NOAA-5 satellite on 24 February 1977. High westerly winds from the Pacific picked up dust as far west as New Mexico and swirled it as high as $4500 \mathrm{~m}$ over Texas. Shown in the photograph are huge concentrations over Texas and as far east as Georgia, with a tongue swinging $>160 \mathrm{~km}$ down into the Gulf of Mexico.

The dust cloud originated from the precious top soil of several midwestern states parched by the area's long drought. The storm continued, although later less severe, for an entire week.

The satellite sensor that detected this storm is called the Very High Resolution Radiometer (VHRR). This sensor has a spatial resolution of $1 \mathrm{~km}$ in the visible channel $(0.6-0.7 \mu \mathrm{m})$ and $1 \mathrm{~km}$ in the infrared (10.5$12.5 \mu \mathrm{m})$. These types of data are available in real time to all countries of the world. The only requirement is that the user must either build or buy the necessary ground receiving equipment.

The ground station used to receive these data is called the Local User Terminal for Meteorology and is located at the Goddard Space Flight Center in Greenbelt, Md. •

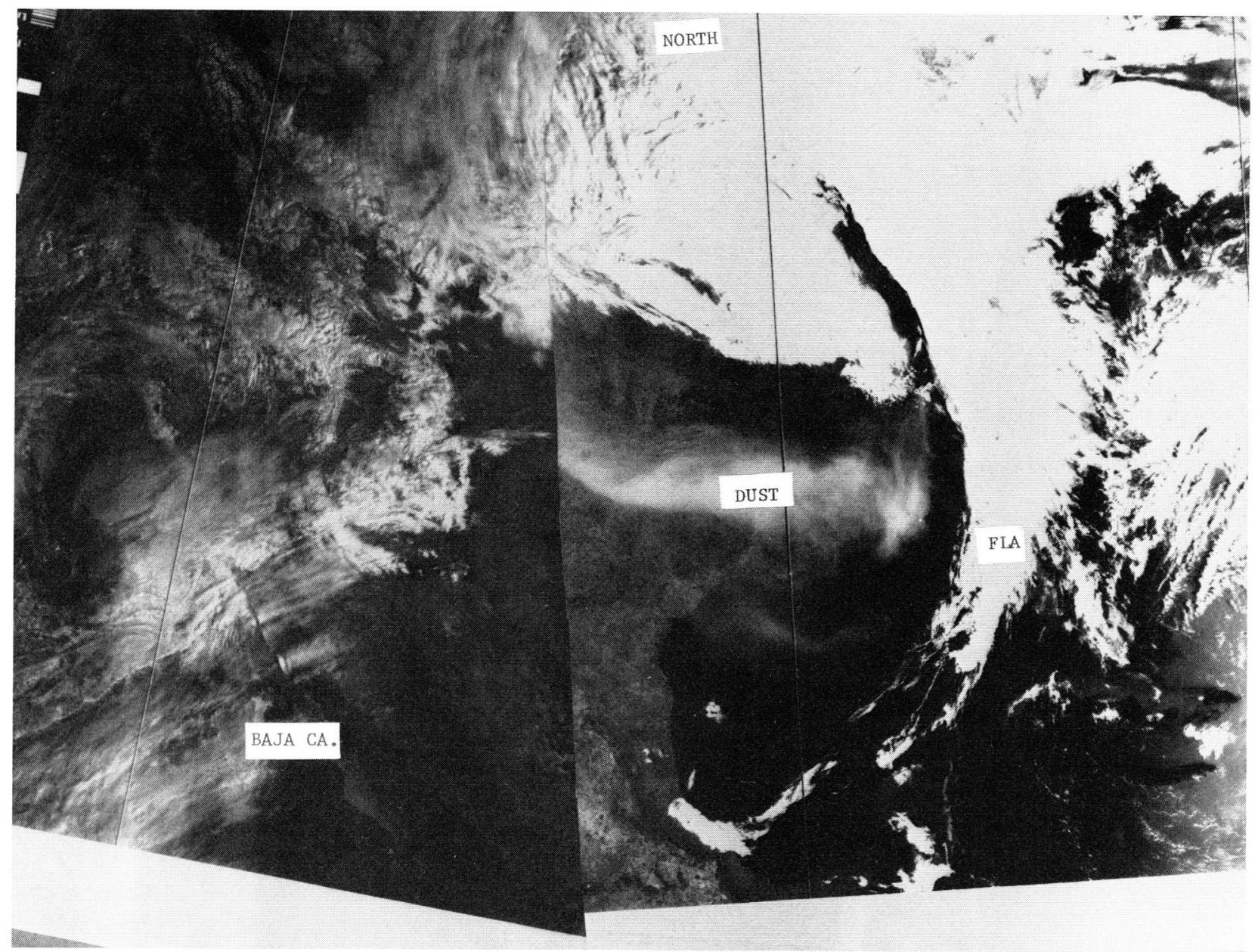




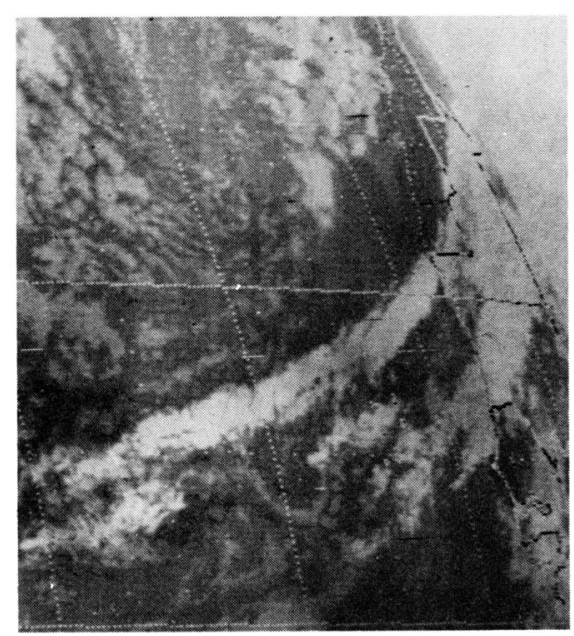

CIRRUS OR CUMULUS?

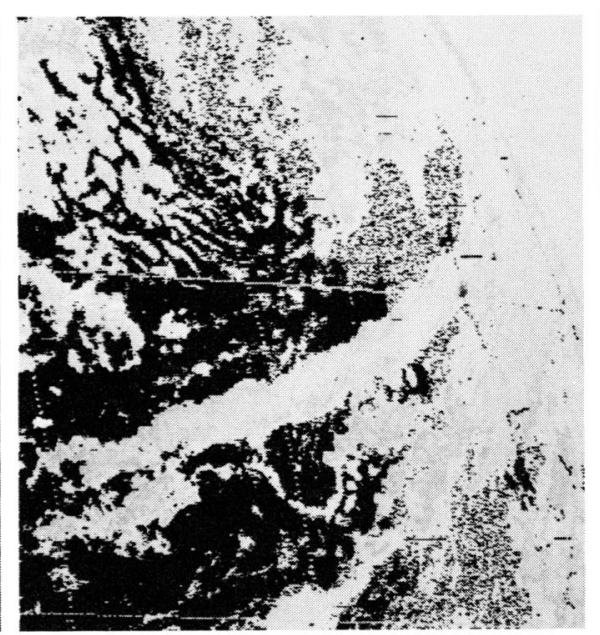

ABOVE 4,000 FEET?

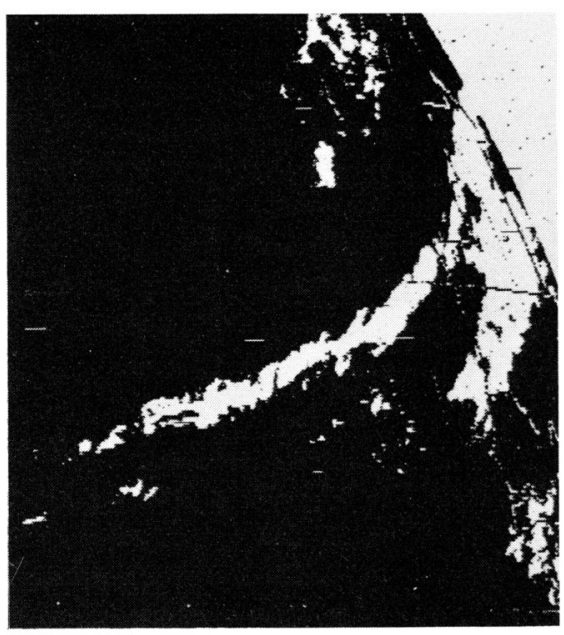

ABOVE 20,000 FEET?

\section{Dial Threshold Data in a Minute . . . for a fraction of what you'd expect to pay.}

Get answers to temperature/ altitude questions your current WEFAX, APT or HRPT (VHRR) images can't provide. Get increased analysis/evaluation capabilities with selective magnification, calibration, panoramic distortion correction, isotherm annotation, much more. Get it all - for $\$ 9,300$ instead of $\$ 80,000$ - in EMR's Model 810 APT Scanning Radiometer Data Manipulator (SRDM), a member of the self-contained digital processor family that interfaces with any existing MET ground station equipment.

With no complex analog controls to set, the SRDM provides a computer-processed image geared to your specific needs.

Easy-to-use digital gamma correction controls provide enhancement, correction of non-linear intensity effects, even thresholding selectivity to as little as $2^{\circ} \mathrm{C}$.

Aspect ratios can be digitally linearized, IR density instantly converted to temperatures within $2^{\circ} \mathrm{K}$, and image areas enlarged up to a factor of 5 without "blockiness" or loss of sensor resolution.
IR isotherms superimposed on the visible image let you pinpoint ocean currents and vegetation. And, for total versatility, you can even add picture reference marks, latitude gridding, and shift the nadir left and right without distortion.

Available in rack-mounting or table-top versions, alone or as part of a complete turnkey system, the versatile, economical SRDM family puts advanced perform ance within reach of any SR station, existing or planned. Shouldn't you be discussing it with EMR today?
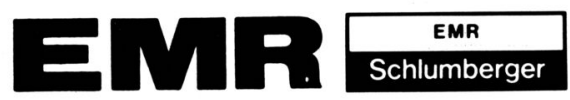

EMR-Telemetry

Weston Instruments, Inc.

Box 3041, Sarasota, Fla. 33578 U.S.A.

(813) 371-0811 